programmes among these vulnerable people so that they can embrace safe and healthy behaviour, such as consistent use of condoms anytime they want to have sex

\section{P4.092 BARRIERS TO ANTIRETROVIRAL TREATMENT FOR HIV PREVENTION AMONG HIV + MEN WHO HAVE SEX WITH MEN IN THE UK: A QUALITATIVE STUDY}

doi:10.1136/sextrans-2013-051184.0990

'S Wayal, 'G Hart, ${ }^{2} \mathrm{~S}$ Edwards, ${ }^{3} \mathrm{~J}$ Cassell. 'University College London, London, UK' ${ }^{2}$ NHS Camden Provider Services, London, UK; ${ }^{3}$ Brighton and Sussex Medical School, Falmer, UK

Background UK and USA guidelines recommend offering antiretroviral treatment (ART) for HIV prevention to patients at risk of sexually transmitting HIV irrespective of CD4 cell count. We explored the attitudes of HIV+ men who have sex with men (MSM) towards use of ART, and ART for HIV prevention.

Methods 24 men (16 on ART and 8 not on ART) attending an HIV clinic in central London, UK participated in semi-structured interviews (May 2010-February 2011). Thematic analysis was conducted. Results Era of HIV diagnosis, and meanings ascribed to CD4 cell count and ART influenced men's attitudes towards starting ART. Men diagnosed with HIV before 2001 considered themselves to be fortunate to be on ART; while those diagnosed later were more likely to have fatalist attitudes and perceived starting ART as resigning to "popping pills for life" and "getting closer to death". They also experienced resentment and lack of control over their health if they felt physically well but were told to start ART due to low CD4 cell count. Most men believed being on ART with undetectable viral load reduces but does not eliminate HIV infectivity, so engaging in unprotected anal intercourse with non-concordant partners (ncUAI) was considered as reckless. However, some men believed that ART reliably prevents HIV transmission and engaged in ncUAI. Men usually discussed their ART/viral load status with partners prior to engaging in ncUAI but some considered this unnecessary due to the reduced risk of HIV transmission. Engaging in UAI with HIV+ men with undetectable viral load was also perceived to reduce the risk of HIV super-infection. Conclusions Health promotion among HIV+ MSM should address fatalistic attitudes towards ART, and negative effects of low CD4 cell count and delaying ART. The limited effectiveness of ART for HIV prevention also needs to be emphasised, along with STI risk.

\section{P4.093 HIV/AIDS RISK REDUCTION AND PREVENTION AMONG DRUG USERS THROUGH BEHAVIOURAL INTERVENTIONS IN AN URBAN SETTING}

doi:10.1136/sextrans-2013-051184.0991

K Galappaththi, M Nissanka, P Sumanasekara. Alcohol and Drug Information Centre (ADIC), Colombo 05, Sri Lanka

Drug use is a major risk factor in spreading HIV infection. Drug users (DUs) might trade sex for drugs or for money to buy drugs and/or vice versa. Drug use can reduce a person's commitment to use condoms and practise safer sex. Often, substance users have multiple sexual partners. This increases their risk of becoming infected with HIV or another STI. Therefore, changing drug-related behaviours contributes to eradication of transmission of HIV.

A behaviour change (BC) model, which directly address BCs than merely conducting awareness/training workshops was implemented in Negombo, a tourist destination located in west coast of Sri Lanka where dwellers are vulnerable for drug use and sex trade. $\mathrm{BC}$ intervention tools used included low-cost community camps, group, ex-user and one-to-one discussions, brainstorming sessions to demystify myths about drug use and HIV while strengthening target groups. Conducted a rapid situation and response analysis, prior to commencing interventions. Interventions concentrated more on 10 specific spots in Negombo. 350 DUs, their families, peers, 170 regular sex partners (RSP) including commercial sex workers (CSW), and neighbours were targeted through interventions.

As a result, of BC model 80 quitted drug use, 59 reduced use, 29 changed their behaviours, 21 work as peer educators, 37 directed to STD clinics. 59 relapsed. The interventions with RSP resulted in following; 32 supported DUs to quit, 35 were educated on safer sex practises, 13 requested for condoms.

BC model resulted in BCs in DUs, RSP, families and in their localities going beyond awareness and education. DUs and RSPs reduced individual risk behaviours, promoted and practised safer sex practises (ex: condom use), motivated to get medical assistance for symptoms and suspected exposure to STDs and if engaged in risky behaviour, to be tested. Changing behaviours related to drug use itself results in HIV risk reduction and prevention.

\section{P4.094 RELATIONSHIP BETWEEN SOCIAL COGNITIVE THEORY CONSTRUCTS AND SELF-REPORTED CONDOM USE: THE SAFE IN THE CITY TRIAL}

doi:10.1136/sextrans-2013-051184.0992

M C Snead, A M O'Leary, M G Mandel, A P Kourtis, J Wiener, D J Jamieson, L Warner, SITC Team (Jeffrey Klausner, Kevin Malotte, LydiaO'Donnell, Kees Rietmeijer, Andrew Margolis). CDC, Atlanta, GA, United States

Background Previous studies have found Social Cognitive Theory (SCT)-framed interventions successful for improving condom use and reducing STIs. We conducted a secondary analysis of behavioural data from the Safe in The City trial to investigate the influence of social cognitive theory constructs on study participants' selfreported use of condoms at last intercourse.

Methods The main trial was conducted (2003-2005) at three public U.S. sexually-transmitted infection (STI) clinics. Patients ( $\mathrm{n}=38,635)$ were either shown a safer sex video in the waiting room, or received the standard waiting room experience, based on their visit date. A nested behavioural assessment was administered to a subsample following their index clinic visit $(n=1,609)$ and at three months follow-up $(n=1,392)$. We used multivariable modified Poisson models to examine social cognitive theory constructs (sexual self-efficacy, self-control self-efficacy, self-efficacy with most recent partner, hedonistic outcome expectancies, and partner expected outcomes) and individual characteristics with self-reported condom use at last sex act.

Results Of 1252 participants included in analysis, 39\% reported using a condom. Male gender, homosexual orientation and single status were significant predictors of condom use. Both unadjusted and adjusted [for demographic variables and study intervention (RR: 95\% CI)] models indicate that sexual self-efficacy (1.50: 1.231.84), self-control self-efficacy (1.67: 1.37-2.04), self-efficacy with most recent partner (2.56: 2.01-3.27), more favourable hedonistic outcome expectancies (1.83: 1.54-2.17), and more favourable partner expected outcomes (9.74: 3.21-29.57) were significantly ( $\mathrm{p} \leq 0.001)$ associated with condom use at last sex act.

Conclusions Social cognitive theory constructs were significantly associated with condom use at last sex act, independent of the video intervention. Social cognitive skills, such as self-efficacy and partner expected outcomes, are an important aspect of condom use behaviour.

\section{P4.095 YOUNG PEOPLE'S KNOWLEDGE, ATTITUDE, AND BEHAVIOUR REGARDING REPRODUCTIVE HEALTH IN THE CONTEXT OF TIRANA, ALBANIA}

doi:10.1136/sextrans-2013-051184.0993

A Subashi. Vitrina University, Tirane, Albania 
Background Adolescents often lack basic reproductive health $\mathrm{RH}$ information, knowledge, and access to health services for RH. Many have less than favourable attitudes and do not feel comfortable to discuss RH with parents or other key adults.

Objectives To assess RH knowledge, attitude and provider preference among adolescents of age 15 to 19 years.

Methods A community-based cross-sectional study was conducted in Tirana Town, capital city of Albania from October 2012 to January 2013. A structured questionnaire was utilised to collect data from the sampled population.

Adolescents aged between 15 to 19 years old were interviewed about their knowledge and attitudes regarding health services for $\mathrm{RH}$. The data were entered into two different computers using SPSS for windows version 17.00. Descriptive analyses using t-test were employed to depict results.

Results The majority of adolescents knew major health services for $\mathrm{RH}$ and the main health service providers of $\mathrm{RH}$.

The major sources of information for $\mathrm{RH}$ were internet radio $92 \%$ and television and radio for $61 \%$ school teachers for $35.9 \%$ and parents $28 \%$ of respondents.

Conclusion The level of knowledge and attitude about health services for $\mathrm{RH}$, source of information for these services and service provider centres is encouraging. However, the role of health professionals and families as the source of information for the adolescents seems to be low. This should be improved using a more integrated all stakeholders particularly adolescents' families and health professionals who have a vital role to ensure adequate knowledge and favourable attitudes for utilisation of the RH in the locality.

\section{P4.096 SEXUAL NETWORK AND PRACTISE OF FEMALE SEX WORKERS IN SIKKIM}

doi:10.1136/sextrans-2013-051184.0994

S Chowdhury, N Panda, M Kundu, R Basu, R Sonkar, S Das Konar, A RoyChoudhury. CINI, Kolkata, India

The problem 'Sikkim is an orthodox state in India. It has a traditional society which believes that polygamy does not exist. There was no authentic study to validate the statement. According to the estimate of 2007, prevalence rate of HIV was 0.6.Though Sikkim SACS is running Targeted Intervention programme, the target population is a hidden one and no penetration is happening by TI' (Valla A, 2006).

A study was conducted on socio sexual network and practise of Female Sex Workers (FSWs) in collaboration with Sikkim SACS in the month of Nov, 2012.

Methodology Sample size was 70 selected through Stratified random sampling (10\% of the total population registered under NGO programmes of Sikkim SACS)

Result and discussion $70 \%$ of respondent is engaged in sex work along with other profession while $30 \%$ is dependent solely in sex work profession. $88 \%$ of respondent is coming to sex work profession for economic reason. Among this $88 \%, 65 \%$ is working for less than 1 year. $70 \%$ of respondent work more than 20 days a month having an average of 30 partners. $80 \%$ of respondent are below age 25 yrs who have more than 30 sexual partners -i.e. less age group is more vulnerable. $80 \%$ of the respondent consumed alcohol. Among $70 \%$ of alcohol users, $90 \%$ is not using condom. $10 \%$ of the respondent taking drug through injecting route. $90 \%$ of respondents have heard of HIV while $30 \%$ of them have accessed TI services. $10 \%$ of respondent explained about STI sign \& symptoms whereas the prevalence rate is $70 \%$.

Conclusion The study shows that polygamy exists in the state and an emerging trend of new FSW noticed. Condom use, knowledge of STI and HIV both are low. The national control programme should develop Sikkim specific design to address these issues.

\section{P4.097 IS THE MINIMUM PACKAGE OF PREVENTION INTERVENTION WORKING? OUTCOME OF COMBINED PREVENTION INTERVENTION AMONGST IN - SCHOOL YOUTHS IN KWARA STATE, NORTH CENTRAL, NIGERIA}

doi:10.1136/sextrans-2013-051184.0995

A Omoloja, 10 Omotoso, ${ }^{1} \mathrm{C}$ Nwuba, ${ }^{1} \mathrm{~S}$ Faromoju, ${ }^{2} \mathrm{~N}$ Ndulue, ${ }^{3} \mathrm{~J}$ Alayande. ${ }^{1}$ Management Sciences for Health (MSH), Ilorin, Kwara State, Nigeria, ${ }^{2}$ Management Sciences for Health (MSH), Abuja, Federal Capital Territory, Nigeria, ${ }^{3}$ Government Secondary School, Bode Sa'adu, Kwara State, Nigeria

Background Adolescents are among the vulnerable groups at risk of HIV infection. In Nigeria,the high HIV prevalence and teenage pregnancies amongst in-school youths underscores the need to implement effective interventions that address risky sexual behaviours and ultimately reduces the transmission of HIV. This study examines the outcome of Combined Prevention Interventions (CPI) amongst in-school youths in Kwara state,Nigeria.

Methods The MSH Nigeria USAID funded ProACT project supports the Kwara State Government to implement effective and sustainable HIV prevention intervention that promotes adoption of abstinence amongst in-school youths. At Government Secondary School, Bode Sa'adu, 30 (13Males, 17Females) students were trained as Peer Educators using the Family Life HIV Education (FLHE) training package. Information for planning effective HIV Prevention interventions for the target population was generated through questionnaires administration and Focus Group Discussions. The knowledge and skills acquired by the PEs were cascaded to other students using the Minimum Package of Prevention Intervention (MPPI), which addresses behaviour change through the combination of prevention interventions targeted at individuals and communities. Each PE formed a cohort group of 10-15 peers and conducted activities under the Abstinence and/or Be Faithful prevention strategies to promote adoption of positive sexual and reproductive health (SRH) behaviour among their peers. Outcome of the prevention intervention on teenage pregnancies pre and post interventions were analysed.

Results Prior to this intervention, about 10-15 unintended teenage pregnancies were recorded annually (from 2005-2011) at the school resulting in school dropout, unsafe abortion and death. However,after 20 months of implementation,number of teenage pregnancies reduced from 11cases in April 2011 to zero in December 2012. In addition,students also acquired life building skills that resulted in their overall academic improvement and wellbeing.

Conclusion Effective implementation of the CPI/MPPI that focuses on addressing individual and community behaviour can go a long way in achieving sustainable positive SRH behaviours among in school youths.

\section{P4.098 HIV AND YOUR BODY - A COMMUNITY BASED HEALTH AWARENESS PROGRAMME: ADVANTAGES OF MULTIDIMENSIONAL COMMUNICATION STRATEGIES ON THE EXAMPLE OF AUSTRIA}

doi:10.1136/sextrans-2013-051184.0996

'B Leichsenring, ${ }^{2} \mathrm{~B}$ Dannoritzer, ${ }^{3} \mathrm{H}$ Garcia, ${ }^{4} \mathrm{G}$ Picher, ${ }^{5} \mathrm{~W}$ Stefanek. ${ }^{1}$ Aids Hilfe Wien, Vienna, Austria, ${ }^{2} H I V m o b i l$, Vienna, Austria, ${ }^{3}$ Positiver Dialog, Vienna, Austria, ${ }^{4}$ LMCVienna, Vienna, Austria, ${ }^{5}$ PULSHIV, Vienna, Austria

Background Progression of chronic HIV-infection, management of comorbidities or coinfection with STIs is significantly influenced by individual dealing with health and lifestyle issues. PLHIV therefore have an increased need for information and support regarding personal health.

Methods "HIV and Your Body" is an international informational programme promoting health awareness in PLHIV. Activists of community and topic related NGOs are annually trained during an 